\title{
El sujeto lésbico en el cine español dirigido por mujeres: el caso de Marta Balletbó-Coll: Costa Brava (1995) y Sévigné (2004)
}

\section{Lesbian Subject in Spanish Cinema directed by Women: the Example of Marta Balletbó-Coll: Costa brava (1995) and Sévigné (2004)}

\begin{abstract}
RESUMEN
En las últimas décadas el cine LGTBI+ español ha evolucionado hacia una representación más numerosa y variada de la diferencia genérico-sexual, sin embargo, la representación de las mujeres lesbianas continúa siendo, aun hoy, muy minoritaria más aún si nos referimos a películas dirigidas por mujeres. En este texto, a través del análisis de dos obras de la directora Marta Balletbó-Coll: Costa Brava (1995) y Sévigné (2004) ahondaré en la construcción de un sujeto lésbico que rechaza ser exhibido de acuerdo a la tradicional objetualización y espectacularización patriarcal. Para ello, evidenciaré como ambos filmes presentan a personajes femeninos empoderados que basan sus relaciones en la sororidad femenina y la autoaceptación de la identidad lésbica.
\end{abstract}

Palabras clave: cine lésbico, cine de mujeres, sororidad, identidad lésbica.

\section{Abstract}

In the last decades the spanish LGBTI+ cinema has evolved toward a more numerous and varied representations of gender and sexual orientation difference. However, the visibility of lesbian women is still insuficient specially if we talk about films directed by women. In this text, through the analisis of two films of Marta Balletbó-Coll: Costa Brava (1995) and Sévigné (2004), I will deepen in the construction of a lesbian subject who rejects to be objectified and espectacularised by patriarcal society. For this purpose, I will pay attention to the way in which both narratives depict empowered feminine characters that base their relations in sorority and self-acceptance of lesbian identity.

Keywords: Lesbian Cinema, Women's Cinema, Sorority, Lesbian Identity.

\section{SUMARIO}

1.- Introducción. 2.- Evolución de la representación de las mujeres lesbianas en España. 3.- La mujer lesbiana como sujeto. 4.- Autodefinición y sororidad. 5.- Consideraciones finales. - Referencias. 


\section{Introducción}

La representación del lesbianismo ha estado marcada tradicionalmente por la invisibilidad y el desconocimiento (Pelayo, 2009: 11) así como por la falta de referentes sobre los que apuntalar el desarrollo de una identidad valorada en términos positivos. Aun así, los pocos ejemplos existentes de este tipo de cine son fundamentales para comprender la manera en la que se ha construido la imagen pública de las mujeres lesbianas. Al igual que en el caso del colectivo LGTBI+ en su conjunto, «en la medida en la que el individuo no posea otras vías de información en torno a este tema, su único conocimiento de la realidad lésbica será indirecto y mediado a través de todo tipo de discursos de la cultura popular» (Pelayo, 2009: 11). Con esto, el papel del cine es fundamental no solo en cuanto a «espejo deformado» de la realidad sino como una herramienta que puede facilitar o complicar la formación de la subjetividad lesbiana.

Si bien el siglo XX supone un considerable avance en los derechos de los grupos minorizados por su identidad genérico-sexual, lo cierto es que la representación de las mujeres lesbianas continúa siendo muy inferior a la de los hombres gais tanto en el cine como en la televisión (García López, 2009: 247). La normalización e institucionalización del colectivo LGTBI+ ha estado mediatizada por la mayor presencia pública del varón homosexual en su posesión del privilegio masculino. Esta situación es comprobable no solo en la mayor representación que los gais tienen en los mass media en comparación con las lesbianas sino también en el mayor interés, cobertura mediática y taquilla que obtienen los primeros sobre las segundas. Es por esta razón, por la que es fundamental rescatar los filmes dirigidos por mujeres que analizan la experiencia lesbiana para así poner de manifiesto tanto la importancia de la tradición representativa como el papel de las mujeres en su realización (Núñez Domínguez, 2010).

La obra de Marta Balletbó-Coll es prácticamente única en la cinematografía española, tanto por su papel como mujer directora como por el tratamiento de lo lesbiano en sus películas, en especial en las dos obras que serán el centro de este trabajo: Costa Brava (Family Album) (1995) y Sévigné (2004). Estos filmes están marcados por el interés de alejarse del estereotipo de la mujer lesbiana objetualizada y carente de complejidad emocional y por lo tanto suponen un claro intento de alejamiento de los paradigmas clásicos masculinos. Son películas que buscan romper con la asociación que vincula lo masculino con aquello que hace mover y avanzar la narración y lo femenino con algo exhibible y objetificable que detiene, y a su vez, cierra la narración (Lauretis, 1984; Mulvey, 1988) ${ }^{2}$. Debido a la especial sensibilidad que muestra en sus obras en la construcción, no solo del sujeto mujer sino de la realidad lésbica, diversas autoras no han dudado en incluir su cine en la tradición fílmica denominada como «Cine de Mujeres» (Camí-Vela, 2004; García-López, 2009) de acuerdo a su definición como:

2 Me gustaría incidir en que en este texto no haré hincapié en la posición que adopta el/la espectador/a de acuerdo a la recepción del filme, tal y como realiza Laura Mulvey (1989) sino que me referiré, más bien, a la espectacularización del sujeto mujer dentro de las narrativas fílmicas como una manera de subalternizar y rentabilizar económicamente su exposición. 
... un cine que establezca una concienciación de los paradigmas de exclusión que han regido la historia, la teoría y la práctica fílmica, cuestione los modelos hegemónicos de representación y que se proponga desnaturalizar la imagen fílmica... (Colaizzi, 2007: 69).

Un punto fundamental que condiciona las representaciones de las mujeres lesbianas es el padecimiento de una doble discriminación: por su identidad de género y por su orientación sexual. A la par que la represión de la identidad lésbica, debe tenerse presente que de acuerdo a la estructura de género las mujeres son consideradas socialmente como «inherentemente patológicas [...] cercanas a una naturaleza infantil y próximas a la patología» (Platero Méndez, 2009: 19). Esto quiere decir que son definidas socialmente como sujetos «desviados» $\mathrm{e}$ «inestables» que necesitan de la tutela de un varón que las asista. A través de este discurso por el que se proclama la inferioridad femenina se despliega un corpus normativo-social y legal- que niega la individualidad y la ciudadanía plena de las mujeres y que las convierte en sujetos que viven en una minoría de edad vitalicia. Esta realidad ha definido un contexto en el que la existencia y las representaciones lesbianas estaban limitadas discursivamente de tal manera que muchas mujeres se veían obligadas a ocultar estratégicamente su sexualidad para así no sufrir esta doble discriminación (Pelayo, 2009: 12). Las obras cinematográficas de Balletbó-Coll, en este contexto, cobran una importancia determinante ya que ofrecen narrativas y personajes que, no solo sirven como referentes para otras mujeres, sino que a su vez visibilizan la mencionada situación de desigualdad social en la que nos encontramos.

En las últimas décadas, muchos han sido los trabajos que han insistido en la importancia de valorar el cine como una producción cultural capaz de formar y modelar el imaginario colectivo (Colaizzi, 2007: 10). La imagen cinematográfica debe ser entendida doblemente como reflejo de la realidad y como agente con capacidad de influir en la misma, es decir, como un dispositivo que, al formar parte de las dinámicas culturales, tiene la capacidad de modificar el devenir histórico, así como dar testimonio del mismo. Gracias a su papel como medio de comunicación de masas, pone al alcance del público historias, discursos y valores que sirven a los diferentes intereses que motivan la realización de una película y que buscan «afectar» a la audiencia entendida como receptora de un mensaje. La recepción del cine LGTBI+ tiene especial relevancia social ya que las luchas políticas, así como las identidades del colectivo están, en muchos casos, condicionadas por las representaciones que se hacen de ellas (Alfeo, 2011: 64).

En este trabajo me centraré en dos puntos fundamentales. Por una parte, la construcción de un sujeto lesbiano complejo alejada de los discursos que lo exhiben en tanto que deleite sexual. Se insistirá en cómo estas películas tratan de deconstruir el paradigma de la normalidad y de la familia tradicional heterosexual a través de la representación de mujeres lesbianas de mediana edad, trabajadoras, autónomas, con motivaciones y deseos propios. Por otro lado, me centraré en analizar como en ambas narraciones -especialmente en Costa Brava- tiene un papel fundamental la autodefinición de la identidad, no como una categorización rígida sino como un proceso dinámico y fluido en el que el papel de la sororidad femenina es indiscutible. 
Para ello realizaré un análisis narratológico (Alfeo, 2011) centrado en desgranar de manera conjunta las similitudes de ambas películas. El análisis discursivo de la narración, es decir, dilucidar cuál o cuáles son las intenciones de la directora en la construcción del texto fílmico, me permitirá conocer a qué obedece la presentación de unos determinados personajes o argumentos. Dicho esto, lo que pretendo es una «hermenéutica de las imágenes» (Zurian y Caballero, 2013) que ponga en relación la intención del filme con el contexto social en el que se presenta, puesto que el mensaje fílmico no puede ser interpretado en su complejidad sin prestar atención al porqué de una representación. Analizar cuáles son los efectos de la narración de acuerdo a sus condicionamientos sociales (Rose, 2002: 15) me permitirá indagar los discursos que están insertos de forma implícita en las historias que se narran y como, en el caso de Balletbó-Coll, suponen un intento de demarcarse del sujeto lésbico construido por el imaginario masculino patriarcal.

\section{Evolución de la representación de las mujeres lesbianas en España}

La representación de las mujeres lesbianas en el contexto español ha pasado por diferentes fases de acuerdo tanto a la intencionalidad política como al contexto histórico. El resultado es un complejo entramado en el que puede vislumbrase como el arquetipo de la mujer lesbiana como objeto sexual tiene especial continuidad (Sánchez del Pulgar Legido, 2017: 104). Durante los años 60 y 70 junto con la popularización del cine de terror, la imagen de la lesbiana es asociada a la figura erotizada de la vampiresa (Melero, 2014: 277) con ejemplos como La noche del terror ciego (Amando de Ossorio, 1971) o la francesa El ataque de las vampiras (Jesús Franco, 1973). Así mismo será frecuentemente utilizada como objeto sexual en las películas «S» o eróticas para satisfacer los deseos y fantasías voyeurísticas del espectador heterosexual como en los largometrajes: Silvia ama a Raquel (Diego Santillán, 1978) y La caliente niña Julieta (Ignacio F. Iquino, 1980).

A través de estos tópicos su imagen quedaba asociada a dos de los discursos más habituales en la representación de la sexualidad desviada: la maldad y la depravación sexual. Este tipo de representaciones encajan en lo que la autora Irene Pelayo (2009: 40) denomina modalidad erótica del cine lésbico, es decir, películas en las que el sujeto lesbiano es sexualizado y objetualizado para así contener el carácter amenazador y castrador que posee para la identidad masculina. Por esta razón, estas películas al igual que otras de temática gay cierran la narración con un final trágico a modo de redención en el que la mujer lesbiana es castigada o redimida por la masculinidad hegemónica representada por el varón heterosexual. Estos textos, muy habituales durante el periodo franquista, buscaban servirse del poder propagandístico del cine para así reforzar y emponzoñar la (in)visibilidad de las mujeres lesbianas.

El final de los años 70 e inicios de los 80 será fundamental para las luchas del movimiento feminista, algo muy relevante de cara a la representación de lo lesbiano. En concreto, el periodo extendido entre 1976, con la celebración de las Jornadas Catalanas de la Dona, y 1978, con la entrada en vigor de la Constitución 
española ${ }^{3}$, destaca por ser uno de gran calado en la reivindicación de los derechos de las mujeres (Nash y Torres, 2009: 80). Durante estos años se puede comprobar como comienzan a aparecer tímidos intentos de largometrajes que van más allá de la estereotipia femenina y lésbica. Películas como Me siento extraña (Enrique Martí Maqueda, 1977) o Carne apaleada (Javier Aguirre, 1978) reflejan esta transición como un experimento que trata de mostrar de forma más sensible la realidad lesbiana sin entrar de lleno en sus problemáticas y manteniendo el carácter erótico que permitía cierto rendimiento económico en taquilla (Pelayo, 2009: 46-47). Tal y como afirma Isolina Ballesteros (2001: 15) «la mujer en el cine de la Transición está en transición» se encuentra en una encrucijada entre la emancipación y la persistencia de los ideales franquistas. Esta situación es especialmente evidente en el cine lésbico con la coexistencia de películas que capitalizan la sexualidad lésbica y otras -en clara minoría- que suponen un primer contacto con la problemática de dicha identidad.

Durante los años 80 y 90, la organización política del movimiento lésbico y la reactivación del movimiento feminista español (Valcárcel, 2006: 432), serán cruciales para el proceso de «independencia» de la mujer que se había forjado en la clandestinidad y tomado forma política tras la muerte del dictador. La legalización del divorcio (1981) y la despenalización del aborto (1985) son claros ejemplos que evidencian el cambio del status de la identidad femenina. Una serie de transformaciones que se reflejan en el que Barbara Zecchi (2004: 332) afirma es rasgo común del cine de los años 90 de autoría femenina: el cuestionamiento de la cosificación de la mujer. El protagonismo femenino será indudable, tanto delante como detrás de las cámaras, especialmente con las figuras de Josefina Molina y Pilar Miró (Ballesteros, 2001: 14). Estas transformaciones en el panorama social y cinematográfico sirvieron también como desencadenante para que las representaciones lésbicas comenzaran a alcanzar cierto grado de variedad. Algunos ejemplos en esta línea son: Pepi, Luci, Bom y otras chicas del montón (Pedro Almodóvar, 1980), Entre Tinieblas (Pedro Almodóvar, 1983), Extramuros (Miguel Picazo, 1985) y Calé (Carlos Serrano, 1986).

El cine de los años 90 y de décadas posteriores estará marcado por el interés de deconstruir la idea de una España culturalmente unificada exhibida por el Régimen franquista (García López, 2009: 234). La multiplicación de las formas de representación de lo lesbiano se producirá, a la par que el surgimiento de películas que tratan lo LGTBI+ como parte de sus tramas, pero sin concederle el peso central de la narración: uno de las consecuencias de la multiplicación en los medios de la presencia homosexual es que esta deja de tener tanta importancia (Mira, 2007: 591). Este cine, ha sido denominado por Irene Pelayo (2009: 47) como

3 Algunos de los cambios más relevantes que introdujo el texto constitucional se deben al Artículo 14 en el que se reclama la igualdad ante la ley sin caber opción a la discriminación por razones varias entre ellas el sexo o la raza. Así mismo se establecía con el Art. 32 el acuerdo de matrimonio en igualdad jurídica entre hombres y mujeres. Otros avances como la despenalización del adulterio y el amancebamiento así como la despenalización de la venta y propaganda de anticonceptivos se producirán a través de la modificación del Código Penal. 
modalidad desfocalizada", en la que el lesbianismo es un "complemento circunstancial o un desencadenante de la acción». Como ejemplos de esta etapa pueden mencionarse las películas El pájaro de la felicidad (Pilar Miró, 1993), Costa Brava (1995) y Pasajes (Daniel Calparsoro, 1996). En los últimos años, obras como Sévigné (2004), Cachorro (Miguel Albaladejo, 2004), 21 centímetros (Ramón Salazar, 2005), Electroshock (Juan Carlos Claver, 2007), Castillos de Cartón (Salvador García Ruíz, 2009), Ander (Roberto Castón, 2009), Habitación en Roma (Julio Medem, 2010), 80 Egunean (José María Goenaga y Jon Garaño, 2010) y El sexo de los Ángeles (Xavier Villaverde, 2012) dan cuenta de los avances socioculturales en la igualitarización social y en la multitud de puntos de vista desde los que se trabajan las relaciones lésbicas. Esto explica la multiplicación de géneros, temáticas y representaciones presentes en el cine LGTBI ${ }^{5}$ a la par que se mantienen e incluso refuerzan los modelos tradicionales (García López, 2009: 234).

\section{La mujer lesbiana como sujeto}

Una vez contextualizado brevemente el cine lésbico y en concreto el de la directora catalana, pasaré a continuación a analizar el contenido y los personajes principales de las dos obras seleccionadas en este trabajo. Ambas, tanto Costa Brava como Sévigné muestran a cuatro mujeres protagonistas que se alejan del modelo erótico de mujer objetualizada imperante en los medios de comunicación de masas. Para ello, Marta Balletbó-Coll construye y desarrolla personalidades sólidas de mujeres empoderadas como resultado de la aplicación de una «mirada feminista y lesbiana» (Camí-Vela, 2005: 29) caracterizada por la relevancia concedida a la intimidad y cotidianeidad así como por el intento de «normalización» del sujeto lesbiano. Ambas películas llevan a cabo una aproximación de carácter intimista (González 2011: 248) que se percibe no solo en la configuración de los espacios o en las elecciones estéticas sino también en la manera en la que se narra la historia, concretamente la relación amorosa. Balletbó-Coll enfatiza los momentos de intimidad, ya sea a través de miradas, diálogos, pensamientos o meros gestos para revelar la complejidad del deseo lésbico frente al intento heterosexista de reducirlo al mero acto sexual entre mujeres. El papel de la directora es fundamental ya que «controls and restricts the normative heterosexual frame of vision by allowing the viewer to see only what she wants to show» (Kim, 2003: 481). De este modo, en ninguna de las dos películas se muestran escenas que vayan más allá de una caricia o un beso

4 La autora aplica esta clasificación de modalidades de cine lésbico en base a la realizada por Juan Carlos Alfeo respecto a la representación de los hombres homosexuales en el cine español (2003). A pesar de que se refiere a la modalidad desfocalizada como una forma de representación que se ha dado de forma intermitente en el cine español, considero que esta se da con especial intensidad durante los años 90. Esta difuminación del sujeto lésbico puede ser puesta en relación con la constitución del movimiento LGTB como un conjunto unificado así como con la progresiva «normalización»e institucionalización del colectivo y de sus representaciones.

5 El propio cambio de la denominación de cine LGTB a cine LGTBI+ expresa la multiplicación no solo de las representaciones dentro de cada colectivo sino también de la incorporación de otras conceptualizaciones para así dar más visibilidad a las mismas. 
priorizando, por ende, la intimidad afectiva sobre la relación sexual explícita. Lo que se pretende con esto es alterar la hegemonía de la mirada masculina haciendo imposible que el/la espectador/a reduzca los personajes a meros objetos del placer escoptofílico sometidos el escrutinio de una mirada controladora (Mulvey, 1988: 5).

Es innegable que el cine español mainstream posee una enorme carencia de escenas sexuales entre mujeres (Collins y Perriam, 2000: 217) que no caigan en las coreografías sexuales diseñadas por y para el imaginario masculino. La tradición representativa del cine lésbico ha estado condicionada por el peso del estereotipo de la modalidad erótica que ha originado que las representaciones eviten la espectacularización de las escenas sexuales (García López, 2009: 252). Mientras que el sexo entre hombres ha sido una constante literaria y fílmica (Collins y Perriam: 2000: 219), las mujeres lesbianas han estado condicionadas por la manipulación patriarcal que se hace de su deseo, bien para convertirlo en objeto consumible, bien para asociarlo a la depravación y al pecado. La renuncia a mostrar explícitamente escenas sexuales obedece a la intención de la directora de alejarse de dicha tradición para así poder explorar el espacio privado e interpersonal de las parejas de mujeres lesbianas.

Si bien es cierto, debe tenerse en cuenta que Balletbó-Coll, más que negar la expresión fílmica del sexo entre mujeres se sirve de formas más sutiles de afectividad. Este acercamiento fílmico se basa en el hecho de que se considera más urgente políticamente el reconocimiento del lesbianismo como opción de vida más que como una orientación del deseo sexual, es decir, se considera necesaria la «normalización»-heteronormalización- del sujeto lesbiano ${ }^{6}$. Al igual que como afirma Paul Julian Smith (1998: 138) sobre el cine postfranquista de Eloy de la Iglesia, de lo que se trata es de construir al «buen homosexual», es decir, al sujeto que a través del rechazo del estereotipo se inserta en las dinámicas de tolerancia social. La directora rechaza las escenas sexuales a la vez que presenta personajes que son fácilmente asimilables para así contener la tensión existente en la aceptación social de la homosexualidad:

...in order to limit social transgression [...] the director stops short of radically challenging accepted conventions as the couple appear to ape a heterosexual partnership, cohabiting, emphasizing the importance of monogamy. (Collins y Perriam, 2000: 218).

6 Las tensiones internas tanto del colectivo LGTBI+ como del feminismo en torno a la «normalización» o rechazo de la misma -feminismo de la diferencia y feminismo de la igualdad-son y han sido uno de los debates más relevantes en España ya desde los años 80. En este sentido, tanto sus personajes como la propia directora manifiestan de forma contundente su rechazo de las «etiquetas» (CamíVela, 2005: 45-46). Balletbó-Coll bebe de una tradición activista que reniega del posicionamiento de la diferencia como estrategia política para así evitar caer en la sectorialización de la realidad. Este pensamiento es especialmente evidente en el rechazo que muchas autoras contemporáneas realizan tanto de la asociación de su trabajo con el feminismo como con la categoría de «Cine de Mujeres» ya que ven ambos apelativos como una manera de minusvalorar su producción y recluirla a un gueto (Zecchi, 2004: 334). 
Sin embargo, esto no quiere decir que el sexo no tenga relevancia en la pantalla. A mi juicio, las elipsis narrativas que se producen en ambas películas van precedidas de todo un lenguaje verbal y no verbal que, no solo no anula sino que intensifica las expresiones de la sexualidad femenina. Al contrario que otros filmes que centran la vivencia lesbiana en el sexo entre mujeres, Balletbó-Coll trata de enfatizar las emociones, la sensualidad y por lo tanto, reafirmar lo lesbiano como un significante que va más allá del contacto físico-sexual. Tomaré para ejemplificar esta argumentación una escena extraída de cada película. Por un lado, destaca un breve fragmento aparentemente insignificante de Costa Brava. Anna y Montserrat se encuentran sentadas en el sofá mientras bromean con la posibilidad de tener sexo esa misma noche. Entre bromas que enfatizan el carácter intimista y cotidiano se dilucida que su relación, que acaba de cumplir tres meses, es tan sexual como romántica. La exposición de la actividad sexual parece no ser necesaria para mostrar la de por sí evidente tensión sexual que existe entre las dos y para que el público reconozca lo que va a ocurrir entre la pareja tras ese momento de juegos.

Por otro lado, presentaré como ejemplo una escena en la que Marina y Julia -Sévigné- recrean un fragmento de la obra teatral que preparan de forma conjunta sobre Madame de Sévigné y su hija la Condesa de Grignan. Esta escena se produce prácticamente al final de la película y sirve, tanto como clausura del conflicto emocional de Julia, como apertura de la que será la relación entre las protagonistas. Balletbó-Coll, al igual que en su primer largometraje, «corta» la exposición del sexo explícito para articularlo a través de caricias, susurros, brazos y besos apasionados. La manera en la que se interrumpe el encuentro sexual consiste en dotar a esta escena de un alto contenido emocional: "[a]s the lesbian couple's libido peaks, the viewer's plummets» (Kim, 2003: 480). Julia se derrumba y comienza a llorar desconsoladamente por primera vez desde la muerte de su hija Tanit. Lo que podía haber sido un momento de claro contenido sexual se transforma en el desenlace del nudo emocional que impedía a Julia aceptar su sexualidad. Una vez más, la directora hace primar lo emocional por encima de lo carnal concediéndole el peso de la narración y dotándolo de complejidad:

[En Sévigné] He tratado de hacer un análisis sobre las complejidades del deseo. Cuando alguien te atrae, no sólo te atrae porque tiene un cuerpo «Danone», sino que intervienen muchos más factores como la autoestima, la relación con la madre y el padre, las experiencias personales vividas anteriormente, tus gustos $\mathrm{o}$ preferencias... (Balletbó-Coll, Entrevista ${ }^{7}$ )

Ambos fragmentos ofrecen miradas y gestos llenos de complicidad, efusividad y, en definitiva, intimidad sexual. Se muestra la antesala de un momento que «se sabe» va a ocurrir y que incluso se anuncia a través de la pregunta explícita: «¿Quieres hacer el amor?». La directora otorga privacidad al sujeto lésbico, no

7 Entrevista realizada por Pau Vanaclocha para la página web Vanavisión. Disponible para su consulta en el siguiente enlace: [http://vanavision.com/2011/08/marta-balletbo-coll-directora-y-actriz-de-sevigne/]. Consultado el 5 de agosto del 2016. 
como una manera de limitar u ocultar el deseo sexual sino más bien de alejarlo de la exposición malintencionada del cine tradicional. Su contradiscurso genera un espacio propio para la mujer lesbiana alejado del estereotipo, pero condicionado por su influencia e incluso determinación.

Otra cuestión relevante a la hora de analizar los filmes es la manera en la que se construyen los personajes en tanto que mujeres empoderadas. En ambas películas las parejas protagonistas están formadas por mujeres autónomas e independientes que tienen éxito laboral gracias a su esfuerzo y dedicación. No dependen de ninguna figura masculina que las mantenga o que pueda retener su autoafirmación. En relación a esto puede destacarse a Julia -Sévigné-, una actriz de teatro reconocida que decide retirarse tras la muerte de su hija pero que acaba regresando a los escenarios manteniendo el reconocimiento social y de la crítica, eso sí, en el papel de directora. Las mujeres protagonistas de estas películas destacan en sus respectivos espacios laborales por su rigurosidad y capacidad de trabajo a pesar de los obstáculos que les son presentados por su género ${ }^{8}$. Su trabajo no es solo una forma de ganarse la vida sino que también es tanto una extensión de su personalidad como una pasión que las estimula en su vida cotidiana9.

Son mujeres con determinación que luchan por conseguir sus metas, las cuales se presentan como uno de los objetivos de la historia (Kim, 2003: 471). Una de las tramas de Costa Brava es que Anna consiga que acepten y monten su monólogo. En el caso de Sévigné tanto Julia como Marina acaban por auto-reafirmarse y superarse, una volviendo a los escenarios como actriz y la otra viendo como finalmente su obra cobra vida sobre las tablas. La historia, por lo tanto, no se reduce a la relación afectiva entre mujeres, sino que profundiza en sus intereses, habilidades y aspiraciones consolidando con ello la presentación de unos personajes con solidez en la narración. Son «mujeres sujeto» que no solo participan de la historia, sino que son las protagonistas y únicas artífices de su avance. Ambas películas -a pesar de las peculiaridades que se mencionarán posteriormente con respecto a Sévigné- están narradas desde la perspectiva de las protagonistas, es decir, la mujer lesbiana ocupa en estos textos la posición privilegiada de sujeto (Collins, 2011: 177).

La dislocación de la mirada masculina se manifiesta también en la escasa presencia de hombres y, más aun, en el limitado poder de acción que poseen en comparación con ellas. Los hombres son reducidos a acompañantes de la historia o a meros telespectadores invirtiéndose la dualidad tradicional entre pasividad femenina y actividad masculina. El único personaje que tiene cierta relevancia es Gerardo, el marido de Julia en Sévigné. Gerardo, que trabaja como crítico cultural, actúa como «falso narrador»: presenta y cierra la historia de cara al público, pero no tiene

8 En un momento dado Montserrat -Costa Brava- que ejerce como profesora de ingeniería en una Universidad barcelonesa señala que ha sido tratada de forma diferente por ser mujer aunque no incide con profundidad en el tema. De igual manera en Sevigné, Gerardo, en su papel de crítico teatral muestra su desconformidad y rechazo con que Julia y Marina representen una obra que tiene como protagonistas a dos mujeres: «No se puede dejar a dos mujeres solas en ese teatro inmenso del Teatro Público, no se puede».

9 Monserrat es profesora de universidad, Anna es guía turística y escritora de monólogos, Marina trabaja en televisión (tras las cámaras) y la ya mencionada Julia es actriz y directora de teatro. 
capacidad para actuar ya que su agencia es reducida a la de mero espectador pasivo de su propia vida, siendo incapaz de detener el desarrollo de la relación lésbica. A pesar de que en su introducción, afirma que él ha tenido que ver en la creación de la obra de teatro ${ }^{10}$ lo cierto es que la narración que se realiza posteriormente está claramente enfocada desde la perspectiva de las dos mujeres. Balletbó-Coll dota a sus personajes femeninos de la capacidad de «hablar», convirtiendo en protagonistas tanto sus acciones como sus puntos de vista y limitando, y en cierta manera silenciando, la capacidad de acción lo masculino hegemónico. Es más, la historia de deseo lésbico, al contrario que la experiencia de Gerardo, se convierte en algo de interés, algo que tiene que ser contado y que, por lo tanto, debe abandonar la situación de invisibilidad en la que se ha mantenido.

Este personaje encarna una clara masculinidad hegemónica (Connell, 1996), es decir, las cualidades que son socialmente asociadas tradicionalmente a ser un "verdadero hombre». Es ese «macho ibérico» que asume un papel de protección y control sobre «su» mujer. Es un hombre autoritario que antepone su bienestar por encima del de Julia y que incluso es capaz de manipular al promotor de la obra para que no sea estrenada. Gerardo sabe que Marina supone una amenaza para su núcleo heteronormativo y por ello intenta evitar por todos los medios que Julia dirija la obra. Sin duda, tanto la historia como el desenlace de la narración sirven para desautorizar su comportamiento otorgándole el papel de gran perdedor: frente a su masculinidad normativa tradicional se muestra un amplio espacio de posibilidades abierto por el deseo lésbico. En el caso de Costa Brava, la inoperancia de la masculinidad es tal que no hay ni un solo personaje masculino principal y la aparición de un hombre se reduce a un compañero de trabajo que insiste en tener una cita con Montserrat y que es rechazado continuamente. Estas películas se enfrentan a la posición de subalternidad de las mujeres a través del enfrentamiento con la masculinidad, arcaica y sexista, que hace que los hombres presentados sean construidos como otredad en un texto dirigido por y para las mujeres (García López, 2009: 236).

Esta contraposición o incluso rechazo de la masculinidad hegemónica tiene un claro exponente en el intento de resignificación del concepto de familia y del de normalidad que han señalado algunas autoras y que se hace patente en estos largometrajes (Kim, 2003: 471; Ituarte Pérez, 2012: 15; Ortega Oroz, 2014: 68). Este discurso que rechaza la idea de una familia normal en el sentido tradicional está presente en ambas películas a través de dos metanarrativas o representación diegética doble (García López, 2009: 236). Me centraré en la ofrecida por Costa Brava ya que es especialmente evidente. A la par que la historia de enamoramiento y posterior relación entre Anna y Montserrat, se introduce a modo de narración paralela el monólogo que Anna tiene intención de montar titulado: «Amarás a tu prójimo».

La protagonista es una madre de una familia tradicional que se autodefine como «comunista» $\mathrm{y}$ «liberal» que, sin embargo, da muestras de su homofobia ante la lle-

10 El fragmento al que me refiero es el siguiente: «Saben, yo he tenido algo que ver con el estreno de esta noche. Quizá a ustedes les gustaría saber cómo esta historia sobre una madre, Madame de Sévigné y su hija, Madame de Grignan, ha llegado hasta aquí. No, no, si a ustedes les interesa, si tienen curiosidad, por mi... bueno, a mí me haría bien hablar de ello. De verdad». 
gada al vecindario de una mujer lesbiana. En un principio el ama de casa construye el modelo arquetípico de lesbiana en base al discurso de la depravación sexual ${ }^{11}$ opuesto a su propia vida heteronormativa y religiosa en la que, añade, es "completamente feliz». Según avanza la película, se insertan fragmentos del monólogo que van mostrando como el discurso del ama de casa evoluciona hasta llegar a tener un encuentro sexual con su vecina y mostrar la realidad tediosa de su matrimonio. La protagonista del monólogo sirve para establecer la homosexualidad y la heterosexualidad como opuestos en un continuo donde la aceptación del lesbianismo supone el cuestionamiento de la unidad y estabilidad heterosexual (García López, 2009: 252).

Esta idea es expuesta visualmente a través de la utilización de un símbolo católico como es la basílica de la Sagrada Familia como fondo del escenario en el que se escenifica el monólogo. La intencionalidad de Balletbó-Coll es clara en lo que respecta a contraponer la narración de la historia de la pareja con las nociones de religión, patriarcado, domesticidad y heteronormatividad que son utilizadas socialmente para dotar de sentido y legitimar la imagen de la familia nuclear heterosexual (Ortega Oroz, 2014: 68). La superposición de las imágenes no es más que la materialización visual de la confrontación que está presente en ambas diégesis: frente a la familia tradicional basada en la rigidez y la tradición se erige una familia marcada por los diferentes momentos de crecimiento personal, intimidad y afecto que se representan en el álbum familiar.

Así mismo, el monólogo no solo sirve como un dispositivo que refleja el proceso de aceptación del lesbianismo a través de la lucha contra el estereotipo (Kim, 2003: 476) sino que además evidencia el carácter liberador de la transgresión del deseo sexual heterosexual ${ }^{12}$. La directora hace evidente esta concepción en ambas películas a través de un lenguaje freudiano recurrente así como a la temática edípica elegida para su segundo filme Sévigné. De esta manera, la concepción freudiana del deseo como represión es alterada y ampliada por el deseo entre mujeres que no puede ser contenido por la Ley del padre (Ituarte Pérez: 2012: 21) ${ }^{13}$. Incluso en el caso de Sévigné, en el que la historia de Julia está marcada por el drama de la muerte de su hija y su falta de superación del mismo, la aparición en su vida de Marina supone la desestabilización de su ya precaria relación con Gerardo. El proceso de enamoramiento que vivirá con Marina, no solo sirve para cuestionar la relación heterosexual sino que además le servirá para poner fin al proceso de duelo. La directora dota a las relaciones lésbicas de la capacidad de ampliar las opciones

11 El fragmento al que me refiero es el siguiente: «Bueno la vecina es...ya saben...es...lesbiana. Yo soy muy liberal, soy comunista pero no quiero que los niños pasen a su jardín. Ya saben, y si un día se encuentran con el equipo olímpico de tenis femenino ¿eh? Y soy muy liberal pero a los niños se les pueden ocurrir muchas cosas».

12 Existen multitud de ejemplos recientes en los que a diferencia de las películas de Balletbó-Coll la relación entre las mujeres no tiene un final feliz. Puede señalarse el filme vasco 80 egunean en el que Antxu una ama de casa decide sacrificar su felicidad con Maite a cambio de permanecer en su hogar con su marido. El deseo lésbico es concebido como liberador pero sin embargo la protagonista decide mantener las cosas tal cual están para no causar daño a su marido.

13 En este sentido destaca el análisis de la película Sévigné en clave psicoanalítica de Ituarte Pérez (2012). 
vitales y laborales de las protagonistas sin que por ello deban renunciar a sus ambiciones individuales.

En este sentido, tal y como afirma la autora Yeon-Soo Kim (2003: 471-472): «[t]he film promotes the acceptance of a lesbian family by stressing the universally sentimental nature of the family attachment». Un sentimiento de pertenencia a un grupo en el que sus integrantes se estimulan mutuamente y en el que no existen relaciones jerárquicas como las descritas en el monólogo del ama de casa o las personificadas por Gerardo sobre Julia. Como resultado se obtiene un «álbum familiar» que no solo sirve como subtítulo de Costa Brava sino que además sintetiza la intención principal de ambas películas: construir un sujeto lesbiano legitimado socialmente: «the family album serves as more than the subtitle of her film. It is a conceptual bridge that connects the lesbian couple with a broader audience» (Kim, 2003: 482).

\section{Autodefinición y sororidad}

El papel del cine en la elaboración de textos culturales que han permitido la afirmación de una identidad social y sexual lésbica ha sido fundamental en las últimas décadas (Collins, 2011: 175). A través de la exposición pública del deseo entre mujeres -en diversos grados e intenciones- se ha conseguido problematizar la identidad lésbica visibilizando, tanto la existencia de mujeres lesbianas, como las particularidades de su situación opresiva. La inclusión de estos sujetos dentro de las narraciones ha permitido que otras mujeres lesbianas se sientan interpeladas por sus vivencias pudiendo identificarse con ellas y estableciendo lazos de pertenencia grupal. El cine ha servido para que, en un momento histórico en que se hablaba más bien poco sobre cualquier sexualidad calificada como "desviada», estos sujetos fueran conscientes de la existencia de «iguales» mitigando, así, el sentimiento de aislamiento pretendido por el sistema patriarcal.

Si hay un rasgo que es habitual en la construcción de textos fílmicos lesbianos es su vinculación con la sororidad femenina: «el lesbianismo es presentado como prolongación de una solidaridad femenina y como alternativa viable a los conflictos presentes en las relaciones heterosexuales» (Zecchi, 2004: 332). Ambas afirmaciones son perfectamente ejemplificadas por las películas seleccionadas en este estudio tanto en las relaciones de confianza y respeto que se establecen entre sus protagonistas como en la alternativa que suponen al modelo de heterosexualidad obligatoria (García López, 2009: 254) representado en un caso por el monólogo del ama de casa y en otro por Gerardo. El cine lésbico de la directora catalana tal y como han señalado otras autoras (Kim, 2003; García Lopez, 2009) puede ser puesto en relación con el continuum lesbiano de Adrienne Rich (1996: 13) y por lo tanto con una forma de entender las relaciones de mujeres que va más allá del deseo sexual y que engloba muchas otras experiencias basadas en la solidaridad común contra el heterosexismo. Es por esta razón que las protagonistas de las dos películas reclaman el espacio legítimo de su orientación sexual sirviéndose de una solidaridad general de las mujeres: «lesbian identity in the film is viewed as part of a whole alliance of women in general» (Kim, 2003: 481). 
En el caso de Sévigné, la comprensión del continuum lesbiano, es decir, de esa experiencia fundamentada en la relación con otras mujeres, cobra un sentido y una amplitud determinantes al vincularlo con la metanarrativa teatral de Madame de Sévigné y su hija Madame de Grignan. Esta película engarza maternidad, lesbianismo y sororidad, no para mostrar una relación incestuosa sino para reflejar una visión del mundo que «conduce por la vía materna a la relación entre mujeres, a una feminización del mundo y a una lesbianización del mismo como subtexto» (Osborne, 2007: 65).

La directora no solo mostrará una identidad lésbica muy vinculada a las relaciones de sororidad entre mujeres sino que insistirá en mostrarla como una entidad que está constantemente «en progreso» (Ortega Oroz, 2014: 70). Mientras que Anna en Costa Brava y Marina en Sévigné -ambas interpretadas por Marta Balletbó-Coll- viven su identidad desde la autoaceptación, Montserrat y Julia ofrecen más resistencia llegando a rechazar explícitamente su categorización como lesbianas en diferentes momentos de los filmes o adoptando diferentes estrategias individuales que les permiten lidiar con el deseo y la atracción hacia otra mujer. Si se toma como ejemplo a Montserrat en Costa Brava puede observarse como este personaje atraviesa diferentes etapas que van desde la negación contundente al cuestionamiento y la aceptación parcial de su identidad. En un principio, su rechazo y omisión de la categorización de lesbiana es evidente a través de la necesidad de autojustificación constante: «siempre he mantenido unas relaciones fantásticas con los hombres, pero al mismo tiempo siempre me ha parecido que faltaba... que faltaba ...algo». Cualquier intento de hacer explícita cierta confusión sobre la orientación sexual va precedido de una afirmación con la que pretende dejar clara su heterosexualidad.

Según avanza la narración, una de las revelaciones de Montserrat -de cara a la audiencia y a la propia Anna- da un nuevo matiz a la problemática identitaria que se plantea. Mientras están sentadas en la calle, Montserrat le cuenta que en el pasado mantuvo, en efecto, una relación de dos años con una mujer que finalizó cuando esta se casó con un hombre. El problema identitario de Montserrat no se basa, de esta manera, en la dificultad para establecer una relación afectiva con otra mujer, algo que ya ha experimentado durante dos años, sino en asumir «lesbiana» como una categoría definitoria que aglutina una serie de experiencias vitales y significados culturales. Esto se hace muy evidente en sus negativas constantes a lo largo del filme: «yo no soy lesbiana». La joven ingeniera comenzará a transformar la manera en la que construye su relación con la categoría «lesbiana» a medida que avanza la narración y su relación con Anna se consolida, pasando de un: «yo no soy lesbiana solo porque me guste acostarme contigo» a un «soy lesbiana pero eso no significa que alguna vez no pueda acostarme con un hombre».

Estas sentencias continúan mostrando el rechazo evidente, así como el miedo a aceptar las consecuencias derivadas de la exposición pública de su sexualidad. Es habitual en este punto que se generen estrategias individuales que, amparadas en la fluidez de lo homosexual y lo heterosexual, busquen reducir o incluso anular las posibles consecuencias sociales de sus elecciones (Cox y Gallois, 1996: 19). 
Montserrat pretende mantener su sexualidad al margen de su vida laboral, es decir, establecer dos espacios diferenciados. Esta decisión se ampara tanto en el ocultamiento de su sexualidad como en la presuposición social que se realiza sobre la heterosexualidad: todo el mundo es heterosexual hasta que se demuestre lo contrario. Montserrat, en un diálogo con Anna, expone su decisión como la más práctica de acuerdo al contexto social homófobo: «la sociedad no está lista para esto». De este modo, amparándose en una supuesta elección racional se exime a sí misma del reconocimiento de su propio miedo e inseguridad y lo vuelca sobre el contexto social. El problema en este caso no es que Montserrat tome una decisión que a priori puede ser lógica debido al contexto homófobo de las instituciones educativas, sino la falsa argumentación que esgrime en la que ni siquiera es capaz de hacer mención a la palabra «lesbiana» ${ }^{14}$. Montserrat puede ser catalogada de acuerdo a la tipología de estrategias establecida por Stephen Cox y Cynthia Gallois (1996: 19) como passer, es decir, como un sujeto que ante el miedo a ser estigmatizado mantiene su vida separada en dos esferas que, espera, no coincidan.

En los momentos finales de la película cuando se comienza a cerrar la narración se produce la última y resolutiva afirmación de Montserrat con respecto a su sexualidad: «soy lesbiana pero... da igual». En cierta manera este modo de dejar inconclusa la frase está revelando la superación de gran parte de las resistencias que le impedían valorar la categoría «lesbiana» como algo positivo o al menos su rechazo directo. Si bien es cierto que la auto-afirmación nunca es absoluta sino que está sometida a las convulsiones y retraimientos propios de las identidades (Eliason, 1996: 54), el que Montserrat no trate de justificarse nos está revelando un gran avance en la comprensión y valoración positiva de su deseo.

Otro aspecto identitario fundamental es la materialización pública de la aceptación que va asociada a una visión más global e integrada de los espacios, alejada de la dicotomización espacial a la que me he referido. En este sentido la película ofrece una clara salida narrativa: ambas protagonistas se irán a los EEUU tanto a cumplir sus sueños como a comenzar «una nueva vida juntas» que se presupone estará marcada por la visibilidad pública. La narración, de este modo, vincula el proceso de desarrollo de la identidad lésbica con el de autorrealización personal: aceptarse como lesbiana tiene consecuencias muy positivas para la vida de Montserrat.

\section{Consideraciones finales}

En este texto he explorado algunos aspectos del cine de Marta Balletbó-Coll con la intención de revalorizar su trabajo como uno de los pocos ejemplos de cine lésbico español que puede ser considerado como producto de una mirada feminista. La construcción de los personajes, los espacios, la narración y la intercalación de

14 En este sentido los autores Susan R. McCarn y Ruth E. Fassinger (1996: 525) afirman que: «a woman may choose to be professionally ccloseted) for important contextual reasons; as long as the choice has been addressed, this woman may be as developmentally integrated as the woman who is profesionally open. However, at some point, as the women lives in society with a clearly defined alternative sexual preference, she will have to address the meaning of lesbianism in that society». 
metanarrativas definen dos historias que dan voz a las mujeres lesbianas como sujetos con capacidad de agencia. Es indudable que la elección de la directora de «suprimir» cierta exposición de la actividad sexual de las protagonistas puede tener efectos contraproducentes en la visibilización de las expresiones sexuales lésbicas. De esta manera, existe un claro riesgo y perjuicio al anular la representación de las escenas sexuales, no solo porque se está cediendo a las presiones del estereotipo sino porque además se está negando la posibilidad de explorar otras vías de representación que persigan reapropiarse y/o desestabilizar la objetualización que pretende la voyeurización (Halberstam, 2008: 59). Así mismo, debe considerarse con cautela la representación de estos personajes de acuerdo a una intención «normalizadora» que persigue integrar lo lésbico en las dinámicas heteronormativas.

Sin embargo, es fundamental recalcar que, a diferencia de otros largometrajes, Balletbó-Coll no demoniza a las identidades no hegemónicas para construir sus personajes. Estos son mujeres empoderadas no solo porque posean capacidad de acción sino porque no necesitan de la subalternización de otros sujetos para reafirmar su identidad. Tómese como ejemplo el cine gay en el que habitualmente se reafirma la identificación con el personaje principal a través de la ridiculización de la figura de la «loca» o el «mariquita» y, por ende, del rechazo de lo considerado como «feminizante» o «emasculador». En Costa Brava y Sévigné no se encuentran estos mecanismos de rechazo sino que los filmes se centran en reflejar el proceso de «liberación» de la identidad lésbica y de su deseo a través de la sororidad y el respeto de/por lo femenino.

Estos filmes deben ser comprendidos de acuerdo a un contexto histórico que ha sexualizado y espectacularizado permanentemente el deseo lésbico. De esta manera pueden ser considerados en tanto que contradiscursos que tratan de alejarse de las representaciones estereotípicas a las que se ha constreñido lo lesbiano, limitando y simplificando sus expresiones culturales. Dicho esto, considero necesario reconocer y fomentar la variedad de perspectivas y de aproximaciones al deseo lésbico para así enriquecer las representaciones y los discursos que lo construyen. En este sentido, tomo las palabras de Jacky Collins (2011: 190) al respecto de la representación lésbica literaria:

Therefore, despite what may appear initially to be opposing perspectives (to work toward or to eschew normalization) regarding the manner in which lesbian literary identities should be presented and elaborated, it is perhaps prudent to encourage proliferation in order to allow for a multiplicity of voices, stemming from a wide range of lesbian writers and characters, the volumen of which would demand society's attention and recognition.

Por último, me gustaría mencionar el necesario ejercicio que lleva a cabo Balletbó-Coll al invertir la mitología heterosexista por la que se considera que las relaciones lésbicas son el fruto del «rencor» de mujeres «dañadas» por el mal trato sufrido por parte de hombres. El deseo lésbico es experimentado como una orientación que obedece a criterios emocionales individuales y no a «traumas» creados para sostener la hegemonía heterosexual. «La existencia lesbiana es representada (...) como 
una descarga eléctrica y potenciadora entre mujeres» (Rich, 1996: 25) y para ello Balletbó-Coll invierte el discurso patriarcal y es ahora la heterosexualidad la que obstaculiza el desarrollo del deseo lésbico. Tanto Costa Brava como Sévigné inciden en proponer una visión de la autoexploración identitaria como un paso necesario para revelar el deseo lesbiano que ha sido oscurecido por el heterosexismo. Frente al esencialismo identitario clásico se plantea comprender la identidad como algo fluido que requiere de constante cuestionamiento.

\section{REFERENCIAS}

Alfeo, Juan Carlos (2011) «Análisis narratológico y sociedad representada: los personajes LGTB en el cine». En Narrativas audiovisuales: los discursos. Estudios de Narrativa. Madrid: Icono14, 1 (2), pp. 63-84.

BALlesteros, Isolina (2001) Cine (ins)urgente: textos filmicos y contextos culturales de la España postfranquista. Madrid, Fundamentos.

Camí-Vela, María Antonia (2005) Mujeres detrás de la cámara: entrevistas con cineastas españolas, 1990-2004. Madrid: Ocho y Medio.

ColaIzzi, Giulia (2007) La pasión del significante: teoría de género y cultura visual. Madrid: Biblioteca Nueva.

Collins, Jacky (2011) «'Sisters Are Doing It for Themselves': Lesbian Identities in Contemporary Spanish Literature». En Vosburg, Nancy y Collins, Jacky. Lesbian Realities/Lesbian Fictions in Contemporary Spain. Reino Unido: Bucknell University Press, pp. 175-190.

Collins, Jacky y Perriam, Chris (2000) «Representation of Alternative Sexualities in Contemporary Spanish Writing and Film». En Jordan, Barry y MorganTamosunas, Rikki. Contemporary Spanish Cultural Studies, Londres, Arnold, pp. 214-222.

Connell, Raewyn W. (1996) Masculinities. California: University of California Press.

Cox, Stephen y GalloIs, Cynthia (1996): «Gay and Lesbian identity Development». En Journal of Homosexuality, 30(4), pp. 1-30.

De Lauretis, Teresa (1984) «Alice Doesn't: Feminism, Semiotics, Cinema». Indiana: Indiana University Press.

Eliason, Michele J. (1996) «Identity Formation for Lesbian, Bisexual, and Gay Persons: Beyond a 'Minoritizing' View». En Journal of Homosexuality, 30(3), pp. 31-58.

García López, Ana (2009) Feminine identity as the site of struggle: The confrontation of different models of femininity in contemporary Spanish cinema directed by women (1990-2005), (Tesis doctoral), Universidad de Bedfordshire

GonzÁlez, Clarissa (2011) «Visibilidad y diversidad lésbica en el cine español: Cuatro películas de la última década». En Icono14, (9), pp. 221-255.

HALBERSTAM, Jack (2008): «Masculinidad femenina». Barcelona: EGALES.

ItUARTE PÉRez, Leire (2012) «El 'romance familiar' sale del armario: la fantasía femenina en Sévigné (Julia Berkowitz)». En Feminismo/s, (19), pp. 13-27. 
KIM, Yeon-Soo (2003) «Family Album as a Portable Home: Marta Balletbó-Coll's Costa Brava (Family Album)». En Revista Canadiense de Estudios Hispánicos, 27(3), pp. 469-484.

MCCARn, Susan R. y FAssinger, Ruth E. (1996) «Revisioning Sexsual Minority Identity Formation: A New Model of Lesbian Identity and its Implications for Counseling and Research». En The Counseling Psychologist, 24(3), pp. 508-534.

Melero, Alejandro (2014) «Arquetipos gay y lesbiano en el cine de la Transición». En Nash, Mary. Feminidades y masculinidades: arquetipos y prácticas de género. Madrid: Alianza, pp. 271-294.

MirA, Alberto (2004) De Sodoma a Chueca. Una historia cultural de la homosexualidad en España en el siglo XX. Barcelona: EGALES.

Mulvey, Laura (1988) Placer visual y cine narrativo, Valencia, Fundación Instituto Shakespeare/Instituto de cine y RTV.

- (1989): Visual and Other Pleasures. Language, Discourse, Society. London, Palgrave Macmillan.

Nash, Mary y Torres, Gemma (Eds.) (2009) Feminismos en la Transición. Barcelona: Grup de Recerca Consolidat. Multiculturalisme i Gènere.

NúÑ̃z Domínguez, Trinidad (2010) «Mujeres directoras del cine: un reto, una esperanza». En Pixel-Bit: Revista de Medios y Educación, (37), pp. 121-133.

Ortega Oroz, Elena (2014) «I'm not, but... I am, but... Identitats lèsbiques en trànsit als films de Marta Balletbò-Coll». En Rodríguez Granell, Ana (Coord.). Identitats en conflicte en el cinema catalá. Barcelona: UOC, pp. 63-79.

Osborne, Raquel (2007) «Entre el rosa y el violeta». En Labrys, études féministes/ estudos feministas, Disponible online en el siguiente enlace: [http://cdd.emakumeak. org/ficheros/0000/0334/Osborne_Raquel___Entre_el_rosa_y_el_violeta_nov07.pdf].

PELAYo, Irene (2009) Imagen fílmica del lesbianismo a través de los personajes protagonistas en el cine español, (Tesis doctoral), Departamento de Comunicación Audiovisual y Publicidad I, Facultad de Ciencias de la Información.

Platero Méndez, Raquel (2009) «Lesboerotismo y la masculinidad de las mujeres en la España Franquista». En Bagoas, 3, pp. 15-38.

RicH, Adrienne (1996) «Heterosexualidad obligatoria y existencia lesbiana». En Duoda: estudis de la diferencia sexual, (10), pp. 15-48:

Rose, Gillian (2002) Visual Methodologies: An Introduction to the Interpretation of Visual Materials. Londres: SAGE.

SÁnchez del Pulgar Legido, Rosa María (2017) «Homosexualidad latente en el cine del siglo XX». En Femeris, 2 (2), pp. 99-118.

SмIтH, Paul Julian (1988) Las leyes del deseo: la homosexualidad en la literatura y l cine español 1960-1990. Barcelona: Ediciones de la Tempestad.

VAlCÁrcel, Amelia (2006) «Treinta años de feminismo en España». En Historia de las Mujeres en España y América latina. Madrid: Cátedra, pp. 415-432.

ZECCHI, Bárbara (2004) «Mujer y cine: estudio panorámico de éxitos y paradojas». En Cruz, Jacqueline y Zecchi, Bárbara: La mujer en la España actual: evolución o involución, Madrid, Icaria, pp. 315-350. 
Zurian, Francisco A. y Caballero, Antonio A. (2013) «¿Tiene la imagen género? Una propuesta metodológica desde los Gender Studies y la estética audiovisual», En Actas del $2^{\circ}$ Congreso Nacional sobre Metodología de la Investigación en Comunicación, pp. 475-487.

Recibido el 6 de septiembre de 2017 Aceptado el 7 de noviembre de 2017 BIBLID [1132-8231 (2017): 29-46] 